\title{
Drought Monitoring Based on Vegetation Type and Reanalysis Data in Korea
}

\author{
Seoyeon Lee ${ }^{1}$, Seung-Jae Lee ${ }^{1, *}$, Keunchang Jang ${ }^{2}$ and Jung-Hwa Chun ${ }^{2}$ \\ 1 National Center for AgroMeteorology, Seoul 08826, Korea; sylee@ncam.kr \\ 2 National Institute of Forest Science, Seoul 02455, Korea; kcjang@korea.kr (K.J.); chunjh69@korea.kr (J.-H.C.) \\ * Correspondence: sjlee@ncam.kr; Tel.: +82-2-871-0234
}

check for updates

Citation: Lee, S.; Lee, S.-J.; Jang, K.; Chun, J.-H. Drought Monitoring Based on Vegetation Type and Reanalysis Data in Korea. Atmosphere 2021, 12, 170. https://doi.org/ 10.3390/atmos12020170

Received: 4 December 2020

Accepted: 23 January 2021

Published: 28 January 2021

Publisher's Note: MDPI stays neutral with regard to jurisdictional claims in published maps and institutional affiliations.

Copyright: (c) 2021 by the authors. Licensee MDPI, Basel, Switzerland. This article is an open access article distributed under the terms and conditions of the Creative Commons Attribution (CC BY) license (https:/ / creativecommons.org/licenses/by/ $4.0 /)$.

\begin{abstract}
Droughts affect economic, social, and environmental aspects in regions such as the Korean Peninsula, where more than $70 \%$ of the area comprises forests; hence, their monitoring is imperative. Despite the many indices and methodologies developed for monitoring, diagnosing droughts using reanalysis data is challenging as the data are characterized by low resolution and simplified vegetation classification. This study utilized a recently released ERA5 reanalysis dataset and its vegetation type information to derive indices that represent meteorological drought. Furthermore, their accuracy in South Korea, based on observation data, was evaluated. The spatio-temporal variability of droughts was analyzed using various factor and correlation analysis methods considering different atmospheric variables and soil moisture. The validity of the method was verified by comparing the observed and obtained data. Soil moisture in the first and second soil layers was sensitive to droughts in low-vegetation areas, thus requiring relatively frequent monitoring of precipitation and evapotranspiration near the topsoil. High-vegetation areas were most affected in the third layers one month after the drought. Hence, forest drought monitoring should consider precipitation, evapotranspiration, and runoff one month in advance. The results obtained herein can be used for forest drought monitoring one month before its occurrence.
\end{abstract}

Keywords: drought; vegetation type; reanalysis; ERA5; drought indices

\section{Introduction}

Droughts occur when the duration of abnormally dry conditions poses a high risk to the local hydrological balance. They cause critical issues for societies, economies, the environment, and human life [1]. Seas surround the Korean Peninsula on three sides, and a mountain range extends from north to south. This causes a considerable variation in precipitation according to region, season, and period, and this gap in precipitation rate is closely related to the drought characteristics of the peninsula. Furthermore, this is a significantly important topic of study as more than $70 \%$ of this peninsula is covered by forests. Various indices have been developed and used for drought monitoring to determine the degrees of drought [2]. Zarei et al. [3] and Ryu et al. [4] quantitatively identified historical drought events using various drought indices and evaluated the variabilities of these indices. Other studies investigated several drought cases to compare drought indices and use them to detect the severity and variability of past drought cases [5,6]. However, there have been difficulties in diagnosing droughts in the forests in South Korea using reanalysis data due to their low resolution and the simple vegetation classification. Therefore, identifying the correlation between droughts and different types of vegetation could help enhance understanding of these drought events and their management. However, research on this correlation is scarce. Studies aimed at associating local vegetation with the severity and causes of droughts should consider various parameters, including the influence of precipitation, temperature, solar radiation, and the water content of the soil.

In this study, recently released reanalysis data were used to derive various indices that represent meteorological drought, and their accuracies in South Korea based on 
observation data acquired from the Korea Meteorological Administration (KMA) were evaluated. Furthermore, this research aims to examine the spatio-temporal distribution of the drought indices based on vegetation type. The reanalysis data included major drought cases in South Korea from 1979 to 2020 based on ERA5 (the latest climate reanalysis database produced by the European Centre for Medium-Range Weather Forecasts (ECMWF)) data at a high resolution of $0.25^{\circ} \times 0.25^{\circ}$. In addition, the over 41.5-year spatio-temporal variability of droughts in South Korea was analyzed using various factor and correlation analysis methods. These methods were used for high-resolution forest drought monitoring based on observations and modeling.

Information on the dataset and a brief explanation of the methods used in this study are provided in Section 2. The main results corresponding to the droughts that occurred within the past 41.5 years over the Korean Peninsula for different vegetation types are delineated in Section 3. Finally, Section 4 contains a summary and concluding remarks.

\section{Materials and Methods}

\subsection{Data}

\subsubsection{Reanalysis Data}

The Korean Peninsula occupies a relatively small and complex area surrounded by three water (sea) bodies. It is located on the eastern coast of the vast Eurasian continent and has a rapid exchange of energy and matter, which causes dynamical weather phenomena. Therefore, first, we needed a reanalysis dataset with a high spatial resolution to sufficiently resolve the Korean Peninsula. Second, we needed a reanalysis dataset with many land cover types to adequately represent the peninsula's complex (natural and artificial) vegetation distribution. Table 1 exhibits a concise and useful comparison among the available popular reanalysis databases inspected in this study. All of the datasets have purposes and strong points and have contributed to significant success in many regions through high-quality research. In many studies around the world, ERA5 data were employed owing to their relatively high resolution $\left(0.25^{\circ} \times 0.25^{\circ}\right)$ and vegetation fraction data, which enable the vegetation type to be classified from low (short) to high (tall). The ECMWF has encouraged researchers to use the ERA5 data instead of ERA Interim. The message from the ECMWF is, "ERA Interim is being phased out. Users are strongly advised to migrate to ERA5." Therefore, we chose ERA5 instead of ERA Interim considering the above two conditions for our study region and the ECMWF's encouragement.

Table 1. Reanalysis databases considered in this study.

\begin{tabular}{ccccccc}
\hline & CFSR $^{1}$ [7,8] & ERA5 [9] & JRA55 $^{2}$ [10] & MERRA2 $^{3}$ [11] & NCEP1 $^{4}$ [12] & NCEP2 $^{5}$ [13] \\
\hline $\begin{array}{c}\text { Resolution } \\
\text { (degree) }\end{array}$ & $0.312 \times 0.312$ & $0.25 \times 0.25$ & $0.562 \times 0.562$ & $0.5 \times 0.625$ & $2.5 \times 2.5$ & T62Gau. \\
Period & $01 / 1980-$ & $01 / 1979-$ & $01 / 1958-$ & $01 / 1980-$ & $01 / 1948-$ & $01 / 1979-$ \\
Vegetation & $05 / 2020$ & $06 / 2020$ & $05 / 2020$ & $04 / 2020$ & $05 / 2020$ & $05 / 2020$ \\
classification & Yes & Yes (high/low) & Yes & No & No & No \\
\hline
\end{tabular}

${ }^{1}$ Climate Forecast System Reanalysis (CFSR); 2 Japanese 55-year Reanalysis (JRA55); 3 Modern-Era Retrospective analysis for Research and Applications, Version 2 (MERRA2); 4 NCEP/NCAR Reanalysis 1 (NCEP1); 5 NCEP-DOE AMIP-Reanalysis (NCEP2) with its Gaussian grid information (T62Gau.)

The parameters used to identify meteorological and soil moisture variability accompanied by a drought event included the monthly average temperatures at $2 \mathrm{~m}$ above the ground, solar radiation on the ground, wind at $10 \mathrm{~m}$ above the ground, soil moisture data, monthly accumulated precipitation, evapotranspiration, runoff, and annual average precipitation. Data corresponding to a period of 41.5 years (January 1979 to June 2020) were used. 


\subsubsection{Observation and Estimated Drought Data}

To derive forest drought indices that accurately simulate droughts in the Korean Peninsula, observation and reanalysis data for South Korea were compared. Data from the fifty-five Automated Synoptic Observing System (ASOS) stations of the KMA (black dots in Figure 1) were used as observation data. To determine whether the drought indices based on the observation and reanalysis data could accurately simulate past drought cases in South Korea, data on past drought cases were collected from the national drought information portal [14], the hydrological weather drought information system [15], and newspaper articles and reports. Figure 1 shows the ERA5 grid points and provinces (indicated by different colors) used to classify the drought cases. The observation data and drought cases also included monthly data corresponding to the 41.5-year period (January 1979 to June 2020), similar to the reanalysis data.

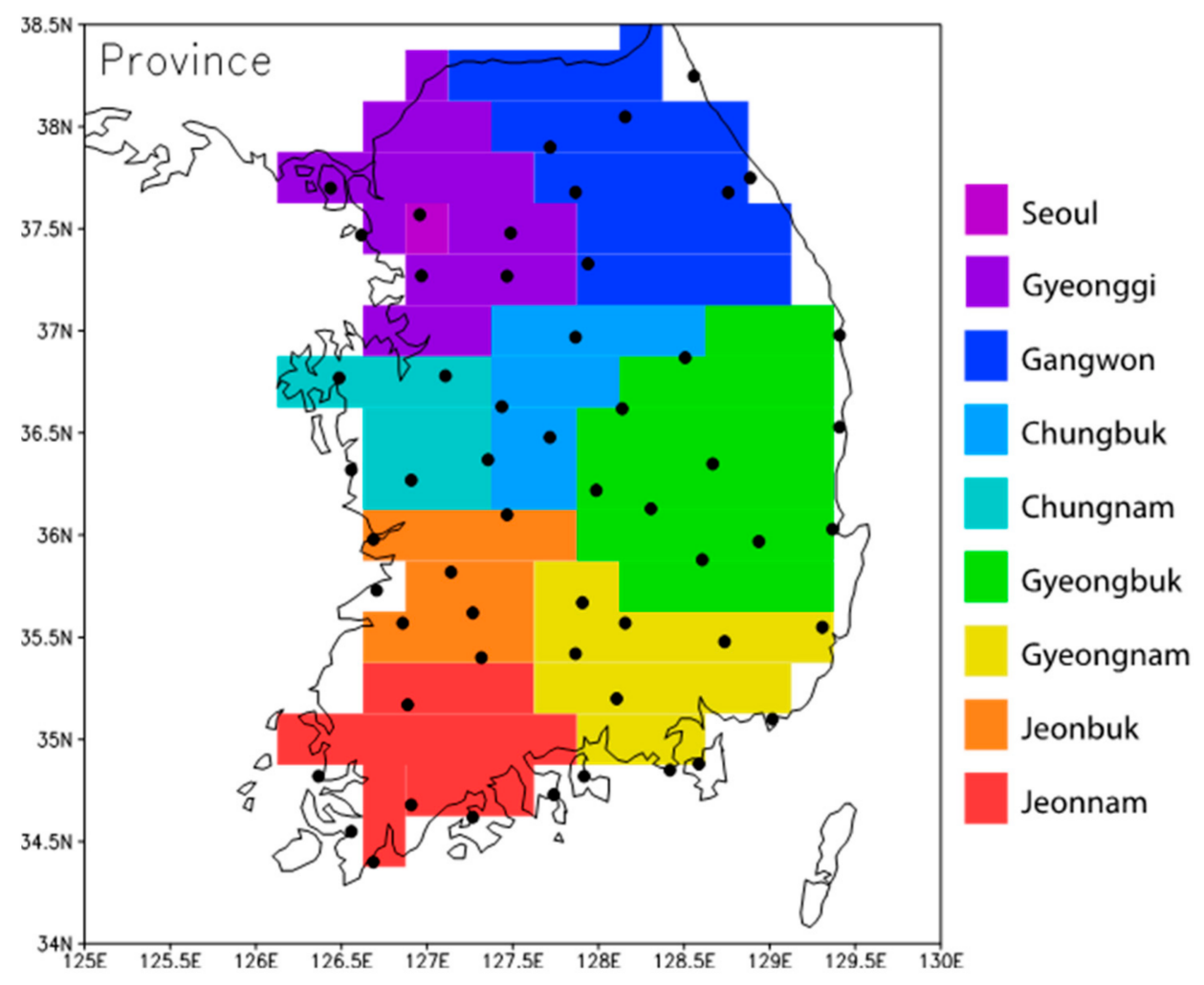

Figure 1. Fifty-five Korea Meteorological Administration (KMA) Automated Synoptic Observing System (ASOS) stations and provinces used for the classification of drought cases. The $0.25^{\circ}$ resolution of the provinces indicates data originating from ERA5.

\subsection{Methods}

\subsubsection{Drought Indices}

The reanalysis and observation data were compared using seven meteorological drought indices that consider only precipitation (Table 2); these indices are relatively simple drought indices. An Interactive Data Language (IDL) software was constructed at the National Center for Agro-Meteorology (NCAM) data server and used to calculate six indices. At the same time, the Standardized Precipitation Index (SPI) was provided by the KMA and Korea Water Resources Corporation (K-water). After determining the seven drought indices for the fifty-five KMA stations and each ERA5 grid point using monthly and yearly accumulated precipitation, the drought indices that most accurately simulated drought in South Korea were determined and compared with the observation data. This allowed the indices' validity in explaining drought variability in the Korean Peninsula using reanalysis data. 
Table 2. Meteorological drought indices used in this study.

\begin{tabular}{ccc}
\hline Index & Full Name & References \\
\hline SPI & Standardized Precipitation Index & McKee et al. [16] \\
EDI & Effective Drought Index & Byun and Wilhite [17] \\
& & Deo and Sahin [18] \\
CZI & China-Z Index al. [19] & Morid et al. [20] \\
MCZI & Modified CZI & Wu et al. [19] \\
& & Morid et al. [20] \\
RAI & Rainfall Anomaly Index & Kraus [21] \\
RD & Rainfall Deciles & van Rooy [22] \\
ZSI & Z-Score Index & Gibb and Maher [23] \\
\hline
\end{tabular}

\subsubsection{Major Vegetation Types}

The vegetation types provided by ERA5 were classified from low to high (i.e., short to tall). The vegetation fractions were classified within these two types. The Korean Peninsula contains several vegetation fractions, including evergreen needleleaf trees, deciduous broadleaf trees, mixed forest/woodland, and interrupted forest, which comprises the high vegetation type. Crops/mixed farming, irrigated crops, semidesert, and evergreen shrubs comprise the low vegetation type. The ERA5 data confirmed that forests account for approximately $70 \%$ of the Korean Peninsula, indicating that they can be reasonably used to conduct the research (Figure 2).

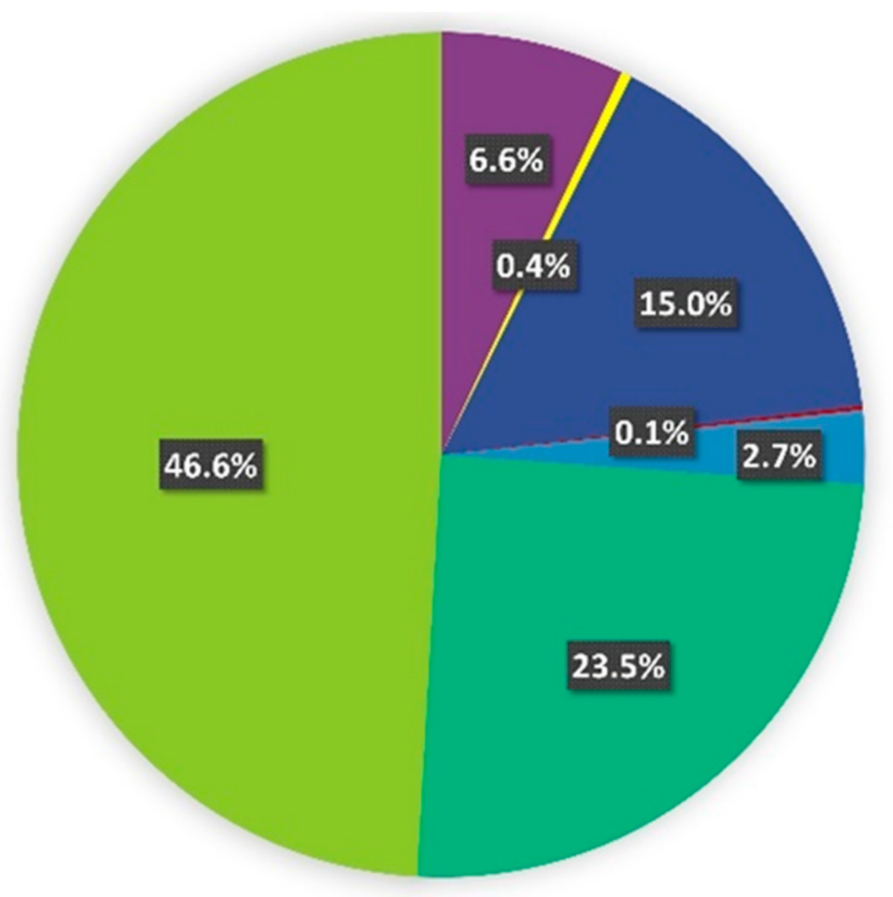

Crops

Mixed farming

Grass

Irrigated crops

Evergreen needleleaf trees

Deciduous broadleaf trees

Mixed forest woodland

Interrupted forest

Figure 2. Vegetation fractions in the Korean Peninsula according to ERA5 data.

In this study, the major vegetation types in the Korean Peninsula were reclassified into eight types (VT 1-8); vegetation fraction of 0.5 or higher (VT 1-5) and vegetation fraction less than 0.5 (VT 6-8) for both vegetation classifications (Figure 3). Additionally, low vegetation was identified as the significant vegetation in VT 1 and 2, whereas high vegetation was identified as the considerable vegetation in VT 3-5. In VT 6-8, the two vegetation types coexisted. 


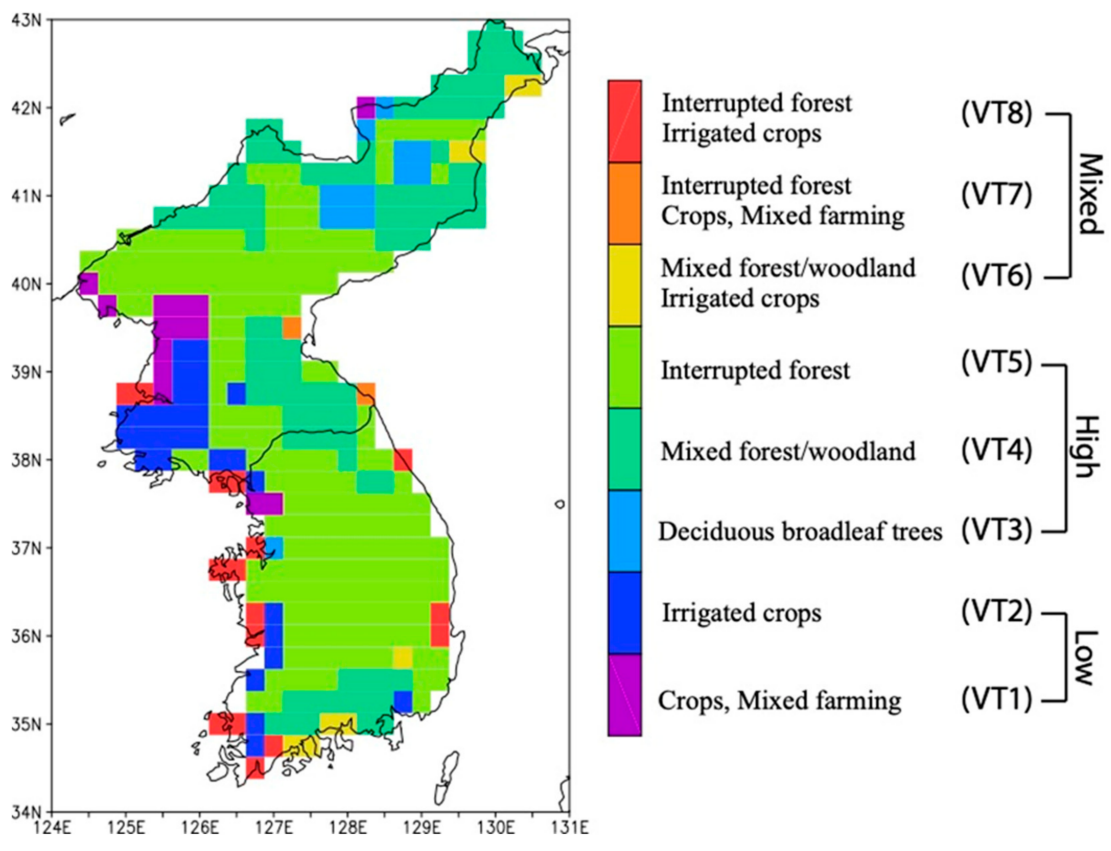

Figure 3. Vegetation reclassification in the Korean Peninsula according to vegetation type and Figure 5 data.

\subsubsection{Hit-Score}

A hit-score was introduced to evaluate the performance of each drought index as well as the suitability of the drought analysis using the reanalysis data corresponding to South Korea. When a drought case was observed based on the drought cases collected in Section 2.1.2, it was classified as a "hit" if all the drought indices at the fifty-five KMA stations and the nearest ERA5 grid points judged the drought cases as a drought (when the index showed a negative value). It was considered a "fail" otherwise (when the index showed a positive value).

\subsubsection{Water Balance Equation}

Given that only precipitation was considered in the calculation of the drought indices, the water balance equation was used for supplementation as follows:

$$
\Delta S \cong P-E-R
$$

According to Equation (1), the change in water storage $(\Delta S)$ is represented by precipitation $(P)$, evapotranspiration $(E)$, and runoff $(R)$. Although other parameters can affect the water balance, their influence is not significant. Therefore, only these three parameters were considered. Here, the change in water storage was used as an index for drought.

\subsubsection{Correlation}

Drought was defined based on the drought indices and $\Delta S$. The correlation and lag-correlation were obtained (Equations (2) and (3)) to examine the correlation between drought and moisture variability in each soil layer.

$$
\begin{gathered}
\operatorname{Corr}(x, y)=\frac{\sum_{k=0}^{N-1}\left(x_{k}-\bar{x}\right)\left(y_{k}-\bar{y}\right)}{\sqrt{\sum_{k=0}^{N-1}\left(x_{k}-\bar{x}\right)} \sqrt{\sum_{k=0}^{N-1}\left(y_{k}-\bar{y}\right)}}, \\
\operatorname{Corr}_{l}(x, y)=\frac{\sum_{k=0}^{N-l-1}\left(x_{k+1}-\bar{x}\right)\left(y_{k+1}-\bar{y}\right)}{\sqrt{\sum_{k=0}^{N-l-1}\left(x_{k+1}-\bar{x}\right)} \sqrt{\sum_{k=0}^{N-l-1}\left(y_{k+1}-\bar{y}\right)}}, l=1,2,
\end{gathered}
$$


where $\operatorname{Corr}(x, y)$ represents the correlation, $\operatorname{Corr}_{l}(x, y)$ represents the lag-correlation, $x$ is the drought index or $\Delta S, y$ is the moisture content of each soil layer, $N$ is the time interval ( $N=13$ in this study), and $l$ is the delay time (one or two months).

\section{Results}

\subsection{Drought Cases (2010-2020)}

Over the last ten years (after 2010), due to rapid climate change, there has been an increase in drought disasters in the Korean Peninsula [14]. To evaluate the annual drought indices obtained from the reanalysis data from 2010 to 2020, drought cases were investigated and compared (Figures 4 and A1). It was observed that severe droughts occurred in South Korea in 2013 and 2017 [14,15,25], and all seven drought indices correctly judged these cases as droughts. Among them, the SPI and Rainfall Anomaly Index (RAI) were more accurate as drought indicators, clearly showing negative signs in both years (Figure 4). Additionally, the drought variability according to vegetation type differed depending on the drought index and severity. In particular, the SPI and RAI exhibited different drought severity levels for each vegetation type with respect to the drought cases that were observed in 2017, and their simulation performances were considered excellent for South Korea. The differences in drought variability between the vegetation types were also then examined.

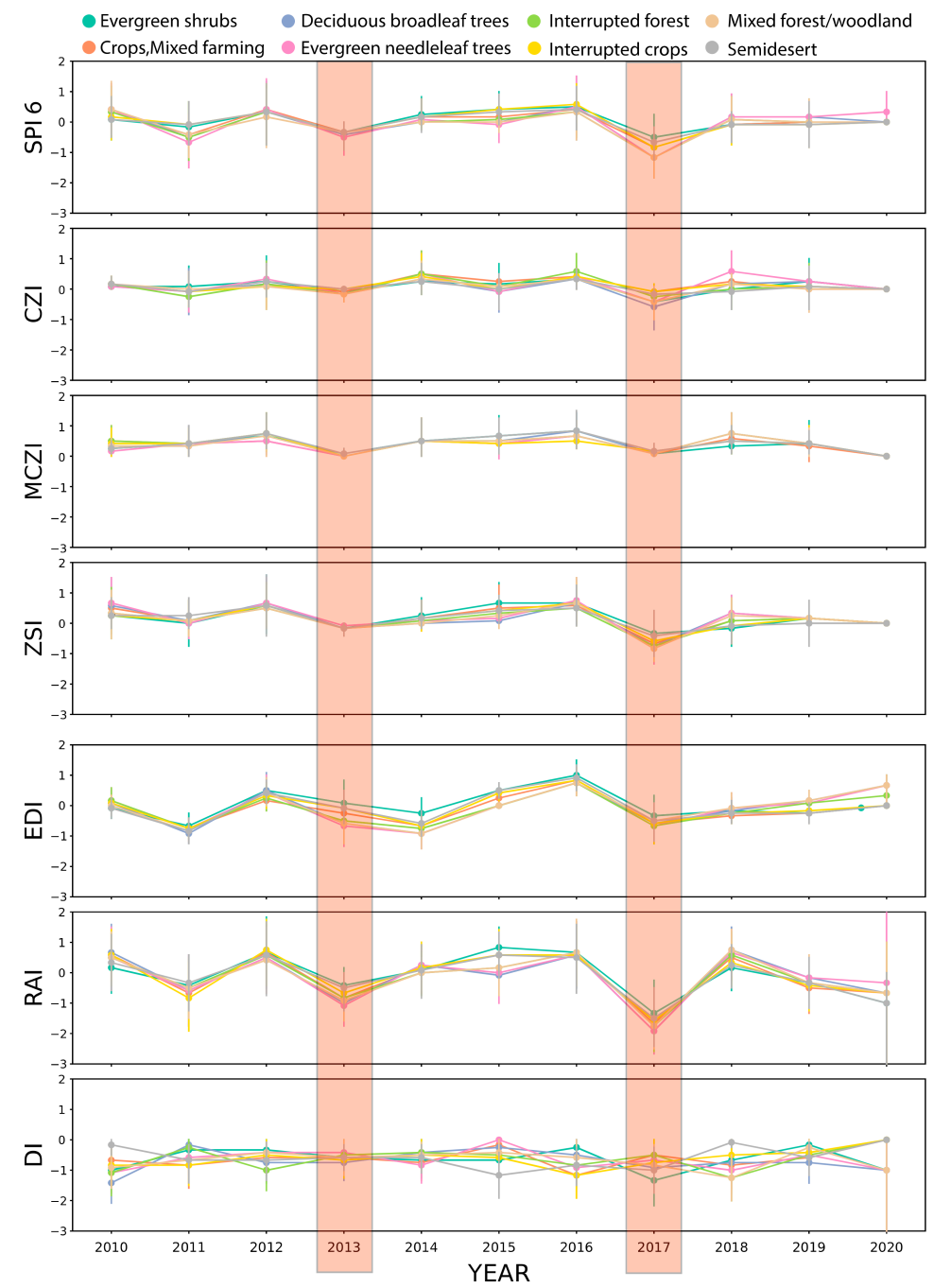

Figure 4. Seven drought indices calculated using ERA5 data for each vegetation type in South Korea (2010-2020). Here, 2013 and 2017, highlighted in red boxes, indicate severe drought years in South Korea. 


\subsection{Hit-Score}

To investigate the drought variability for each vegetation type in the Korean Peninsula based on the reanalysis data, each drought index's performance and suitability for drought analysis using the reanalysis data were evaluated, given that observation data are available for this part of the peninsula. The hit-scores of each drought index at the observation points (fifty-five KMA stations) and the nearest ERA5 grid points were obtained for the monthly drought cases over the 41.5-year period (Table 3). The hit-scores of the drought indices calculated using ERA5 were similar to those of the indices calculated using KMA. These findings indicate that the RAI (74.1\%) best simulated the drought cases in South Korea, followed by the Effective Drought Index (EDI; 66.5\%) and the DI (43.2\%).

Table 3. Hit-scores at fifty-five KMA stations and corresponding ERA5 grid points for drought cases.

\begin{tabular}{ccccccccc}
\hline & & SPI 6 & CZI & DI & EDI & MCZI & RAI & ZSI \\
\hline \multirow{2}{*}{ KMA } & Hit & $26.7 \%$ & $13.3 \%$ & $43.3 \%$ & $68.4 \%$ & $1.1 \%$ & $\underline{74.4 \%}$ & $20.4 \%$ \\
& Fail & $8.4 \%$ & $7.5 \%$ & $17.0 \%$ & $31.1 \%$ & $14.0 \%$ & $25.6 \%$ & $7.7 \%$ \\
\hline \multirow{2}{*}{ ERA5 } & Hit & $29.8 \%$ & $14.6 \%$ & $43.2 \%$ & $66.5 \%$ & $2.7 \%$ & $\underline{74.1 \%}$ & $24.9 \%$ \\
& Fail & $11.4 \%$ & $9.3 \%$ & $18.2 \%$ & $32.9 \%$ & $15.2 \%$ & $25.9 \%$ & $10.5 \%$ \\
\hline
\end{tabular}

Furthermore, annual/monthly analysis confirmed that the RAI best simulated the drought cases in South Korea, and the suitability of the recent reanalysis data was also established. Subsequently, a drought analysis for each vegetation type was conducted using the reanalysis data by expanding the analysis area to cover the entire Korean Peninsula.

\subsection{Drought According to Vegetation Type}

Both the RAI, which was determined to simulate drought in South Korea best, and $\Delta S$, commonly used for drought analysis, are based on precipitation. However, $\Delta S$ also considers evapotranspiration and runoff. To identify the difference in the degree of drought based on these two parameters, annual drought was analyzed for each vegetation type, as shown in Figure 5. Each panel represents one of the eight vegetation types. The black lines represent the normalized $\Delta S$, and the red lines indicate the RAI. The star-shaped marks represent the minimum values over the study period. There was a relatively high correlation between the two indices, but the years showing the minimum RAI and $\Delta S$ values differed in VT 2, 5, 7, and 8, where interrupted forest or irrigated crops were included. This implies that more complex surface processes and land-atmosphere interactions occurred during these years compared to other years.

For a more detailed analysis of drought according to vegetation type, a composite analysis was conducted considering a period of approximately six months based on the ten minimum RAI values (Figure 6, Table A1). In VT 1 and 2, where low vegetation is predominant, the soil moisture variability in the first and second layers was higher than 1.5 standard deviations (STD); this represents a significant influence and indicates that the root zone immediately responded to drought given that there were fewer leaves and roots compared with areas with high vegetation. For soil moisture in the third layer, the water content exhibited the minimum value with a one-month lag from drought. This may have a significant influence on vegetation, especially during forest drought. However, in the fourth layer, the impact of drought was not significant based on the RAI obtained. For soil moisture in the first and second layers, the maximum RAI and correlation were 0.747 and 0.626 , respectively, at 0-lag. In the third layer, the correlation was 0.555 , with a one-month lag. Additionally, for VT 2 and 8, a two-month lag was observed in the fourth layer. Given that areas with high vegetation changed slowly in response to drought signals for ten drought cases with low precipitation, the drought factors were identified considering the evapotranspiration of vegetation. Therefore, it was necessary to determine each drought indicator using $\Delta S$ by considering precipitation and evapotranspiration. 


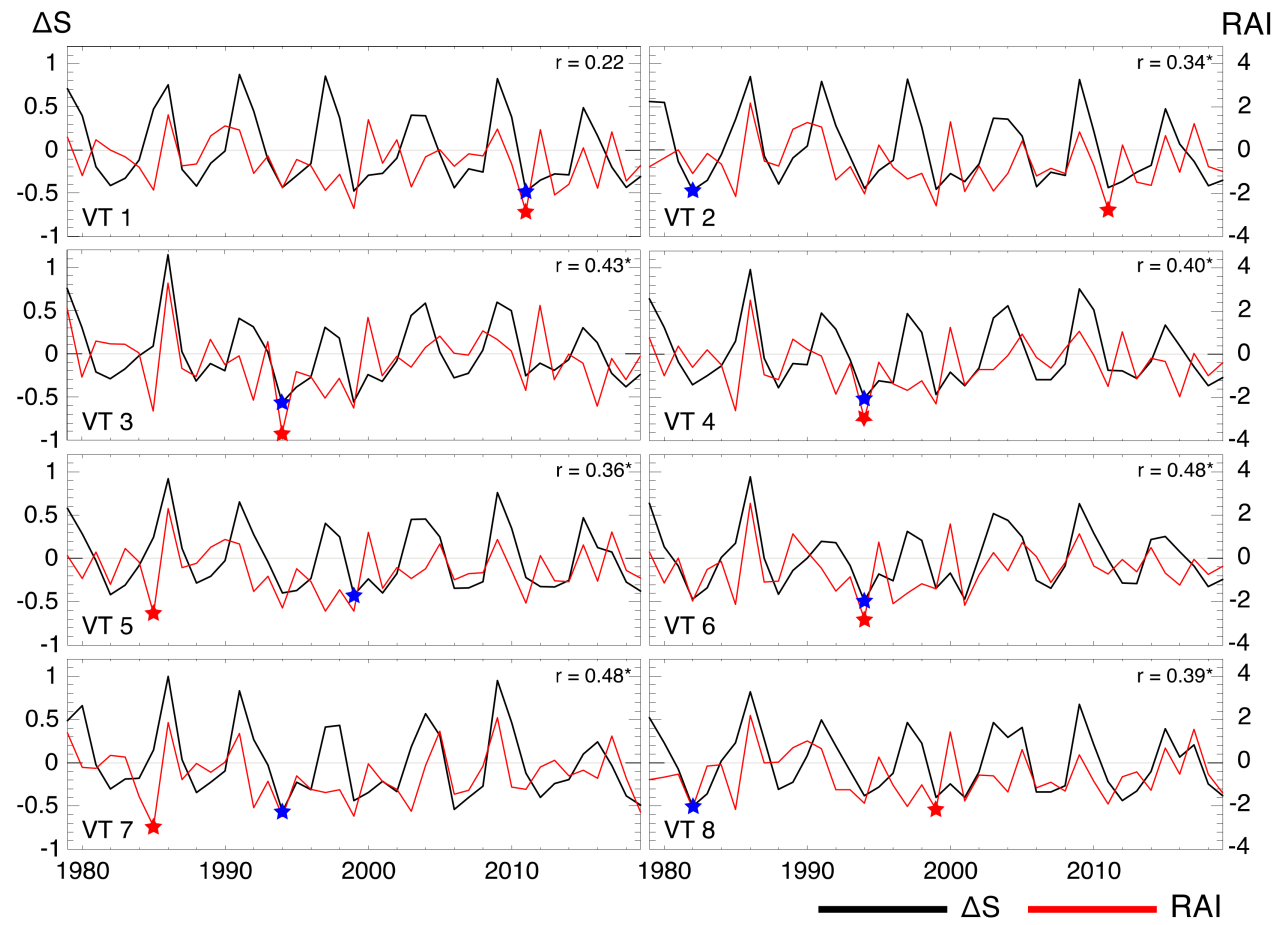

Figure 5. Annual drought for each vegetation type calculated using ERA5 data in the Korean Peninsula. Black line, $\Delta S$; red line, Rain Anomaly Index (RAI); blue star, minimum value in $\Delta S$; red star, minimum RAI values; * , statistically significant at the 0.05 level.
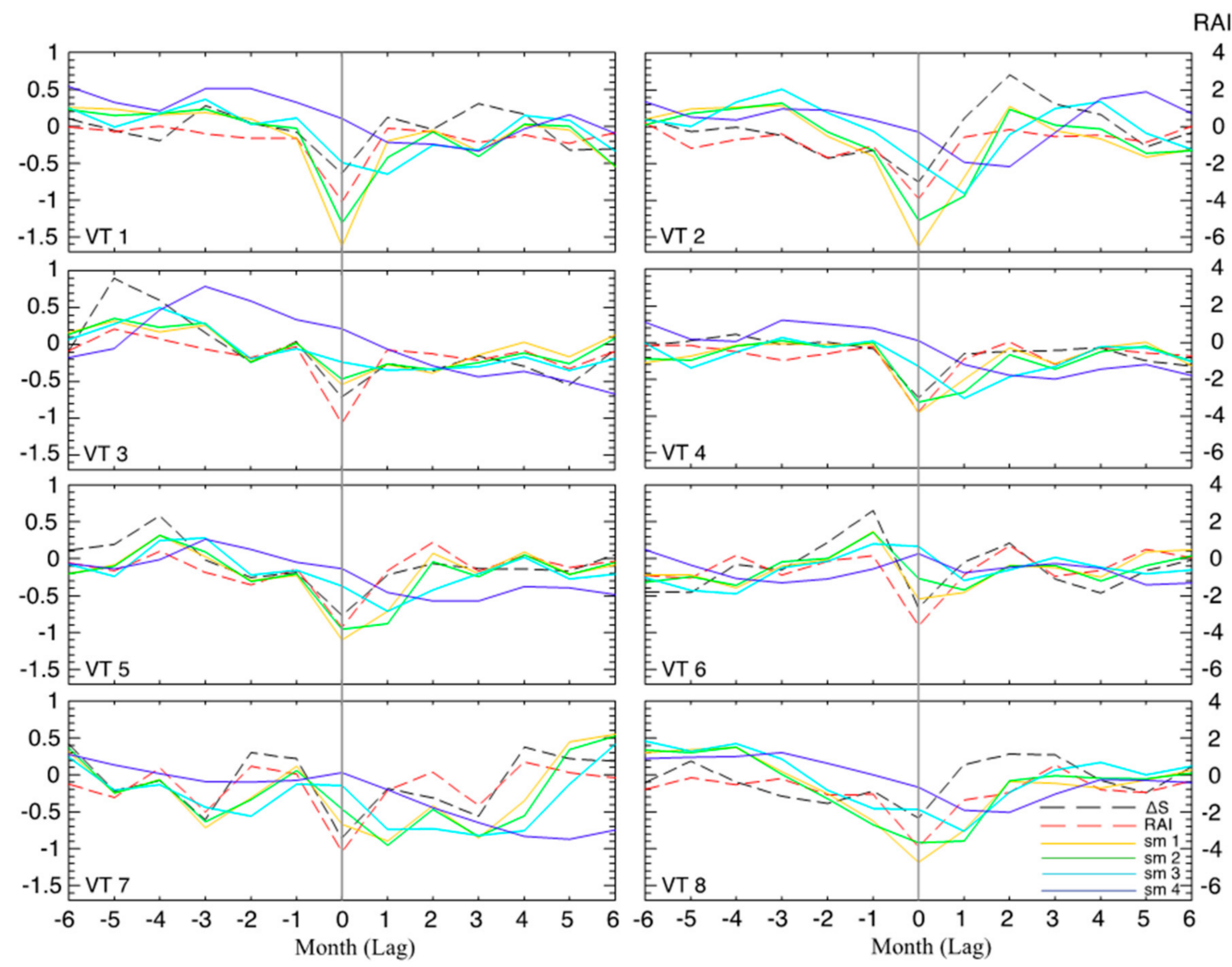

Figure 6. Results of composite analysis based on the ten minimum RAI cases for each vegetation type; $\Delta S$, black dotted line; RAI, red dotted line; soil moisture in the first layer (sm 1), solid yellow line; soil moisture in the second layer (sm 2), solid green line; soil moisture in the third layer (sm 3), sky blue solid line; and soil moisture in the fourth layer (sm 4), solid blue line. All the values from $\Delta S$ and sm 1-4 are normalized and indicated on the left y-axis. 
For cases in which soil moisture significantly affected vegetation, the drought was examined using $\Delta S$ (Figure 7, Table A2). The responses of the vegetation to drought were mostly similar for the same vegetation type, but further analysis is required given that some differences were also observed. The overall characteristics of the parameters indicated that high temperatures ( $\mathrm{t} 2 \mathrm{~m})$, increased solar radiation (ssr), and low east-west wind (u10) are dominant before the occurrence of droughts. Furthermore, soil moisture in the first layer rapidly responded to $\Delta S$ and exhibited a fast water content recovery, as shown in Figure 6. In the second layer, a tendency similar to that of the first layer was observed, but the rate of water content recovery was lower. Soil moisture in the third layer was affected by drought with an evident one-month lag, and in the fourth layer, it exhibited no significant correlation with the drought index. Considering soil moisture in the first and second layers, the results also indicated that low vegetation showed more sensitivity to drought than other vegetation types. Therefore, in such areas, precipitation and evapotranspiration must be monitored at higher-frequency intervals. In areas with high vegetation, such as forests, the lower soil layers (third and fourth) were affected one month after the occurrence of drought, but a higher soil moisture recovery rate occurred compared to areas with low or mixed vegetation types. Overall, one month after a drought occurs, a rapid lack of moisture in the root zone of the forest area may be observed, so it is possible to monitor forest drought one month before its effects are observed.

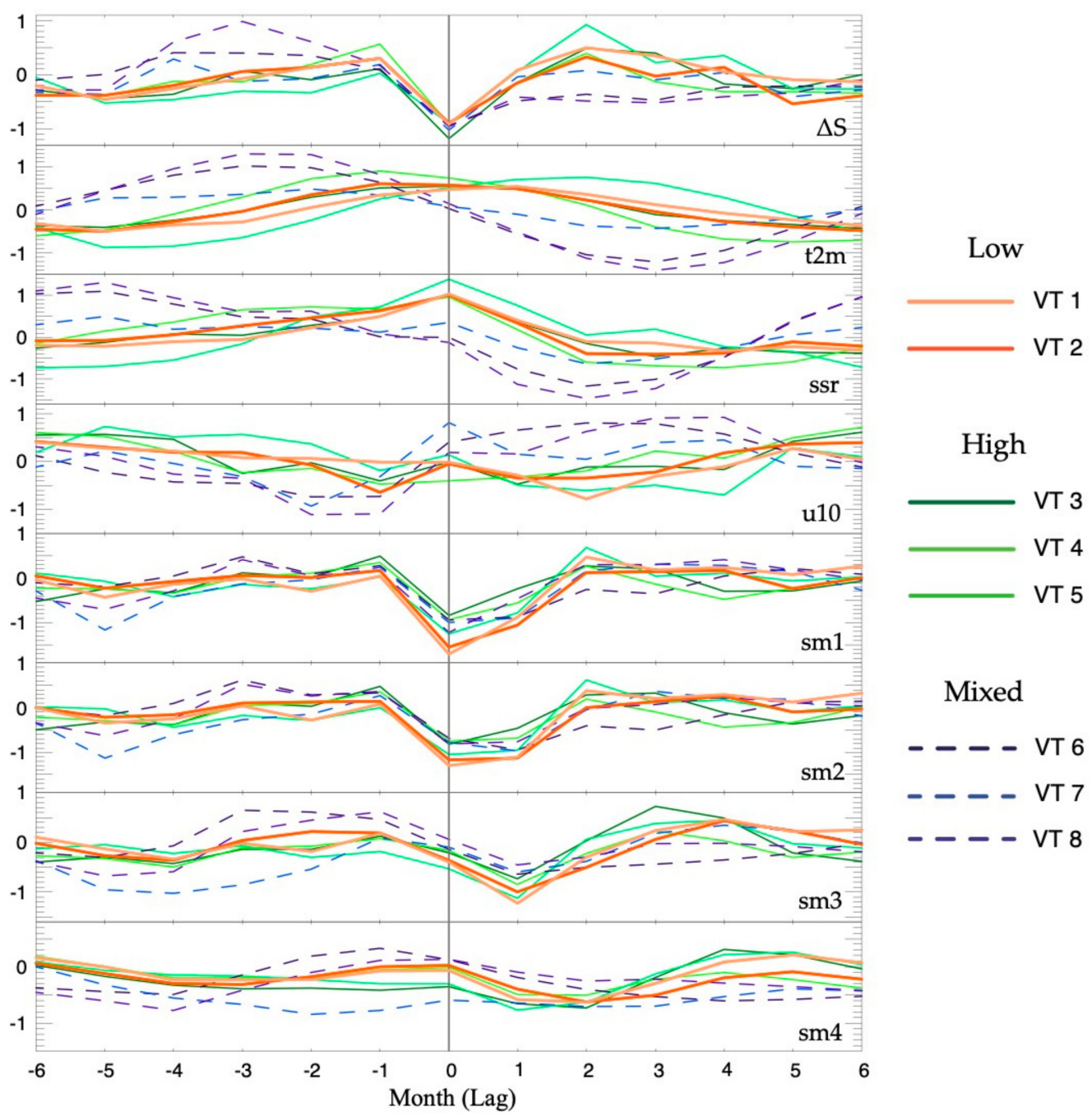

Figure 7. Parameters subjected to the composite analysis based on the ten minimum $\Delta S$ cases for each vegetation type (orange, green, and blue tones correspond to low, high, and mixed vegetation, respectively). $\mathrm{t} 2 \mathrm{~m}, 2 \mathrm{~m}$ air temperature; ssr, surface solar radiation; $\mathrm{u} 10,10 \mathrm{~m}$ U-component of wind. 


\section{Conclusions}

The validity of using recent reanalysis data to examine drought in the Korean Peninsula was verified by comparing observation data with the drought indices obtained from reanalysis data. The use of indices, namely the RAI, EDI, and SPI, showed highly accurate results. Additionally, a drought analysis for each vegetation type was conducted using the drought indices based on precipitation, and the results indicated high soil moisture variability in areas dominated by low vegetation. Given that high temperatures, high solar radiation, and low zonal wind are dominant before a drought, these parameters were considered essential for drought monitoring. Soil moisture in the first and second layers showed a rapid response to precipitation, solar radiation, and runoff. In contrast, the third layer (which significantly influences the forest areas) was affected by drought with a one-month lag. Therefore, it is possible to prepare for forest drought by considering precipitation, evapotranspiration, and runoff one month in advance. The results of this study are expected to be effectively used for devising forest drought monitoring strategies that can be applied one month before drought occurrence. For this purpose, data from mountain weather observation networks can be employed, although the observation period involved is short. These limitations could be addressed by calculating the climatology using the reanalysis and KMA data closest to each observation point. In this study, given that forest density was not considered, there is a limit to the prediction of forest drought based on forest density. In addition to the vegetation fraction, further studies should consider vegetation density, which can have a devastating effect on forest drought.

Author Contributions: Conceptualization, S.-J.L. and S.L.; Methodology, S.L.; Software, S.L.; Validation, S.-J.L. and S.L.; Formal Analysis, S.L.; Investigation, S.-J.L. and S.L.; Data Curation, S.L.; Writing-Original Draft Preparation, S.L.; Writing—Review and Editing, S.-J.L.; Visualization, S.L.; Supervision, S.-J.L.; Project Administration, K.J. and J.-H.C. All authors have read and agreed to the published version of the manuscript.

Funding: This research was funded by the National Institute of Forest Science, grant number FE05002018-02-2020, and the Korea Institute of Planning and Evaluation for Technology in Food, Agriculture and Forestry, grant number 120099-03.

Acknowledgments: This research was supported by the National Institute of Forest Science, grant number FE0500-2018-02-2020, and the Korea Institute of Planning and Evaluation for Technology in Food, Agriculture and Forestry, grant number 120099-03.

Conflicts of Interest: The authors declare no conflict of interest. The funders had no role in the design of the study; in the collection, analyses, or interpretation of data; in the writing of the manuscript, or in the decision to publish the results. 


\section{Appendix A}
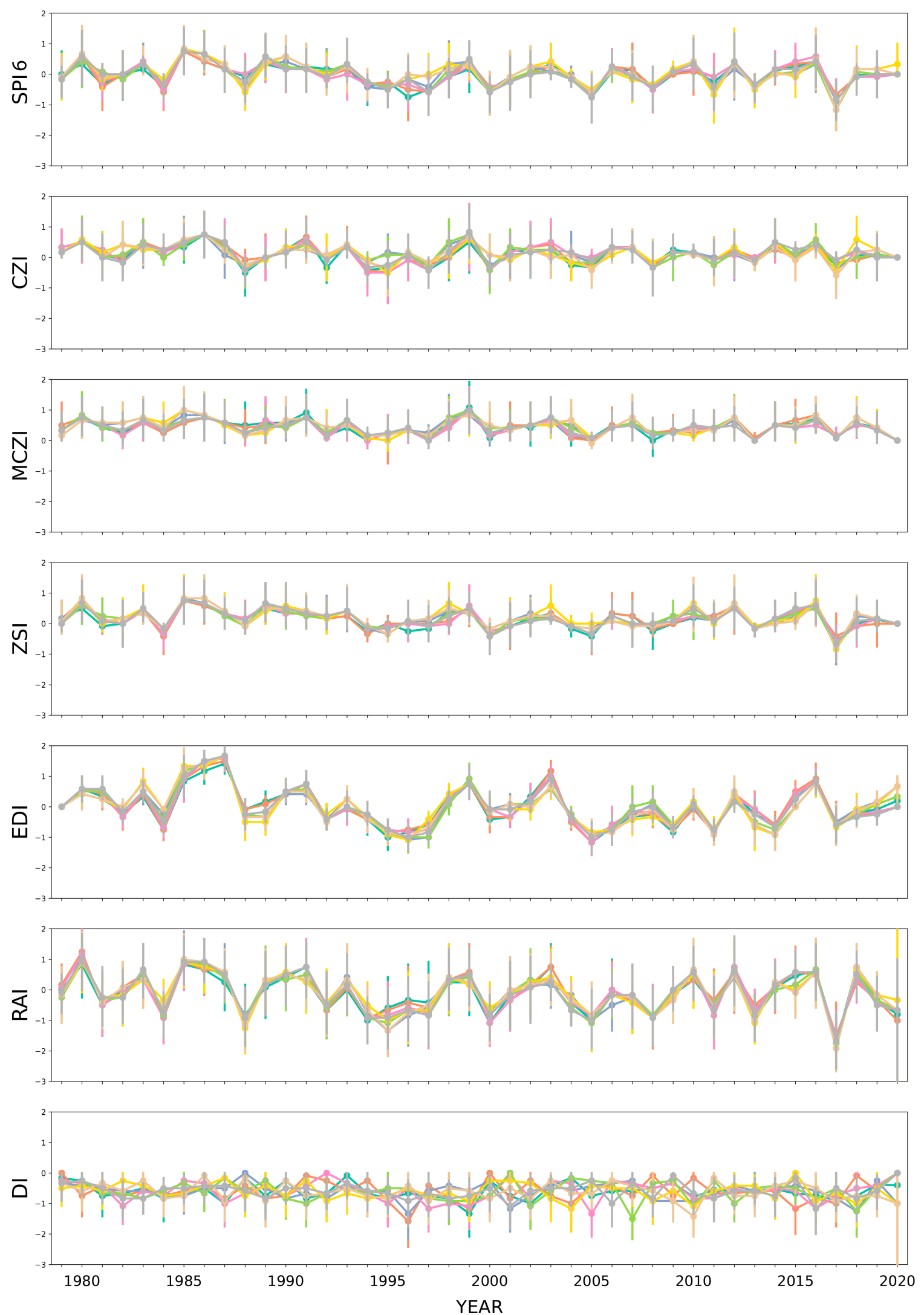

Figure A1. Seven drought indices calculated using ERA5 data for each vegetation type in South Korea (1979-2020). 


\section{Appendix B}

Table A1. Observation dates and values of the ten minimum RAI cases for each vegetation type in Figure 6.

\begin{tabular}{|c|c|c|c|c|c|c|c|c|c|}
\hline & & VT 1 & VT 2 & VT 3 & VT 4 & VT 5 & VT 6 & VT 7 & VT 8 \\
\hline \multirow[b]{2}{*}{1} & Value & -4.56 & -4.32 & -4.78 & -4.25 & -4.16 & -3.91 & -5.09 & -4.09 \\
\hline & Date & Aug. 2000 & Aug. 2000 & May 2018 & Feb. 2004 & Feb. 2004 & Aug. 2000 & Nov. 1996 & Nov. 1993 \\
\hline \multirow{2}{*}{2} & Value & -4.35 & -4.28 & -4.70 & -4.09 & -4.12 & -3.90 & -4.34 & -4.09 \\
\hline & Date & Aug. 1981 & Jul. 2010 & Feb. 2004 & May 2018 & Aug. 2000 & Dec. 2009 & Jan. 1982 & Sep. 2016 \\
\hline \multirow{2}{*}{3} & Value & -4.24 & -4.08 & -4.54 & -4.01 & -3.89 & -3.76 & -4.30 & -4.02 \\
\hline & Date & Feb. 2004 & May 2018 & Aug. 2000 & Aug. 2000 & Jul. 2010 & Nov. 2017 & Jun. 2001 & Aug. 2000 \\
\hline \multirow{2}{*}{4} & Value & -4.10 & -4.03 & -4.33 & -3.92 & -3.87 & -3.70 & -4.30 & -3.98 \\
\hline & Date & May 2018 & Aug. 1981 & May 2007 & Nov. 1996 & May 2018 & Oct. 1981 & Nov. 1993 & Oct. 1981 \\
\hline \multirow{2}{*}{5} & Value & -4.05 & -3.87 & -4.17 & -3.70 & -3.76 & -3.65 & -4.11 & -3.98 \\
\hline & Date & Aug. 2013 & Oct. 1981 & Apr. 2011 & Jul. 2010 & Oct. 2016 & Nov. 1993 & Jun. 1979 & Jul. 2010 \\
\hline \multirow{2}{*}{6} & Value & -4.05 & -3.81 & -4.16 & -3.70 & -3.58 & -3.62 & -3.96 & -3.95 \\
\hline & Date & Nov. 1996 & Feb. 2004 & Dec. 2004 & Mar. 2001 & Jan. 1982 & Feb. 2004 & May 2018 & Nov. 2017 \\
\hline \multirow{2}{*}{7} & Value & -3.97 & -3.80 & -4.08 & -3.61 & -3.51 & -3.58 & -3.93 & -3.77 \\
\hline & Date & Jul. 2010 & Sep. 2000 & Apr. 2001 & Oct. 2016 & Apr. 2005 & Jan. 1997 & Jan. 2009 & May 2018 \\
\hline \multirow{2}{*}{8} & Value & -3.88 & -3.70 & -3.98 & -3.46 & -3.51 & -3.50 & -3.88 & -3.72 \\
\hline & Date & Oct. 2016 & Sep. 2011 & Mar. 2001 & Jan. 2008 & Mar. 2001 & Dec. 2001 & Dec. 1991 & Apr. 1995 \\
\hline \multirow{2}{*}{9} & Value & -3.86 & -3.62 & -3.98 & -3.44 & -3.45 & -3.48 & -3.84 & -3.70 \\
\hline & Date & Feb. 1990 & Apr. 1995 & Aug. 2013 & Aug. 2013 & May 2010 & Jun. 2001 & Jul. 2014 & Oct. 2016 \\
\hline \multirow{2}{*}{10} & Value & -3.83 & -3.53 & -3.98 & -3.42 & -3.38 & -3.47 & -3.82 & -3.68 \\
\hline & Date & Nov. 2018 & Oct. 2016 & Nov. 1996 & Mar. 1988 & Mar. 1988 & Jan. 2008 & Jul. 2003 & Jun. 1999 \\
\hline
\end{tabular}

Table A2. Observation dates of the ten minimum $\Delta S$ cases for each vegetation type in Figure 7.

\begin{tabular}{ccccccccc}
\hline & VT 1 & VT 2 & VT 3 & VT 4 & VT 5 & VT 6 & VT 7 & VT 8 \\
\hline 1 & Jan. 2006 & Jan. 1982 & Jan. 2017 & Sep. 2018 & Sep. 2018 & Jan. 1997 & Apr. 2017 & Jan. 1982 \\
\hline 2 & Oct. 1981 & Oct. 1981 & Sep. 2018 & Oct. 2016 & Jan. 1982 & Mar. 2017 & Aug. 1994 & Feb. 2015 \\
\hline 3 & Oct. 2016 & Jan. 2006 & Sep. 2014 & Feb. 2004 & Oct. 2016 & Feb. 2004 & Feb. 2015 & Mar. 2017 \\
\hline 4 & Jan. 1982 & Sep. 2011 & Jan. 2008 & Jan. 1982 & Sep. 2014 & Feb. 1997 & Apr. 2014 & Feb. 1991 \\
\hline 5 & Feb. 2004 & Sep. 2018 & Jan. 2014 & Jan. 2017 & Oct. 1981 & Feb. 1990 & Jan. 1982 & Feb. 1997 \\
\hline 6 & Jan. 2015 & Feb. 2004 & Jan. 2006 & Jan. 2008 & Feb. 2004 & Feb. 2005 & Feb. 1991 & Feb. 1992 \\
\hline 7 & Jul. 2004 & Jan. 1994 & Sep. 2001 & Jan. 2006 & Sep. 2011 & Feb. 1979 & Feb. 1980 & Feb. 2004 \\
\hline 8 & Aug. 1981 & Aug. 1981 & Feb. 2004 & Jan. 1997 & Sep. 1983 & Jul. 2010 & Sep. 1979 & Feb. 1990 \\
\hline 9 & Sep. 2011 & Feb. 2005 & Sep. 1986 & Sep. 2001 & Sep. 1982 & Mar. 2001 & Sep. 2018 & Feb. 1979 \\
\hline 10 & Aug. 2000 & Sep. 2016 & Jul. 1991 & Oct. 1981 & Jul. 2010 & Feb. 1992 & Jan. 1994 & Mar. 2010 \\
\hline
\end{tabular}

\section{References}

1. American Meteorological Society. Glossary of Meteorology, American Meteorological Society. Available online: http://glossary. ametsoc.org/wiki/Drought (accessed on 1 November 2020).

2. World Meteorological Organization (WMO); Global Water Partnership (GWP). Handbook of Drought Indicators and Indices; Svoboda, M., Fuchs, B.A., Eds.; Integrated Drought Management Programme (IDMP), Integrated Drought Management Tools and Guidelines Series 2; Drought Mitigation Center Faculty Publications: Geneva, Switzerland, 2016; ISBN 978-92-63-11173-9.

3. Zarei, A.; Asadi, E.; Ebrahimi, A.; Jafary, M.M.; Malekian, A.; Tahmoures, M.; Alizadeh, E. Comparison of meteorological indices for spatio-temporal analysis of drought in Chahrmahal-Bakhtiyari Province in Iran. Hrvat. Meteorološki Časopis 2017, 52, 13-26.

4. Ryu, J.H.; Lee, D.R.; Ahn, J.H.; Yoon, Y.N. A comparative study on the drought indices for drought evaluation. J. Korea Water Resour. Assoc. 2002, 35, 397-410. [CrossRef] 
5. Spinoni, J.; Barbosa, P.; de Jager, A.; McCormick, N.; Naumann, G.; Vogt, J.V.; Magni, D.; Masante, D.; Mazzeschi, M. A new global database of meteorological drought events from 1951 to 2016. J. Hydrol. Reg. Studies 2019, 22, 100593. [CrossRef] [PubMed]

6. Kang, D.H.; Nam, D.H.; Kim, B.S. Comparison of meteorological drought indices using past drought cases of Taebaek and Sokcho. J. Korean Soc. Civ. Eng. 2019, 39, 735-742.

7. Saha, S.; Moorthi, S.; Pan, H.; Wu, X.; Wang, J. The NCEP Climate Forecast System Reanalysis. Bull. Am. Meteor. 2010, 91, 1015-1057. [CrossRef]

8. Saha, S.; Moorthi, S.; Wu, X.; Wang, J. The NCEP Climate Forecast System Version 2. J. Clim. 2014, 27, 2185-2208. [CrossRef]

9. Hersbach, H.; Bell, B.; Berrisford, P.; Hirahara, S.; Horányi, A.; Muñoz-Sabater, J. The ERA5 global reanalysis. Q. J. R. Meteorol. Soc. 2020, 146, 1999-2049. [CrossRef]

10. Kobayashi, S.; Ota, Y.; Harada, Y.; Ebita, A.; Moriya, M.; Onoda, H. The JRA-55 reanalysis: General specifications and basic characteristics. J. Meteorol. Soc. Jpn. Ser. II 2015, 93, 5-48. [CrossRef]

11. Gelaro, R.; McCarty, W.; Suárez, M.J.; Todling, R.; Molod, A.; Takacs, L. The modern-era retrospective analysis for research and applications, version 2 (MERRA-2). J. Clim. 2017, 30, 5419-5454. [CrossRef] [PubMed]

12. Kalnay, E.; Kanamitsu, M.; Kistler, R.; Collins, W.; Deaven, D.; Gandin, L. The NCEP/NCAR 40-year reanalysis project. Bull. Amer. Meteor. 1997, 77, 437-472. [CrossRef]

13. Kanamitsu, M.; Ebisuzaki, W.; Woollen, J.; Yang, S.K.; Hnilo, J.J.; Fiorino, M.; Potter, G.L. Ncep-doe amip-ii reanalysis (r-2). Bull. Amer. Meteor. 2002, 83, 1631-1644. [CrossRef]

14. National Drought Information Portal. Available online: http://www.drought.go.kr/menu/m30/m32.do (accessed on 20 July 2020).

15. Hydrological Weather Drought Information System. Available online: https://hydro.kma.go.kr/droughtU/droughtGis.do (accessed on 20 July 2020).

16. McKee, T.B.; Doesken, N.J.; Kleist, J. The relationship of drought frequency and duration to time scales. In Proceedings of the 8th Conference on Applied Climatology, Anaheim, CA, USA, 17-22 January 1993; pp. 179-183.

17. Byun, H.R.; Wilhite, D.A. Objective quantification of drought severity and duration. J. Clim. 1999, 12, 2747-2756. [CrossRef]

18. Deo, R.C.; Şahin, M. Application of the extreme learning machine algorithm for the prediction of monthly Effective Drought Index in eastern Australia. Atmos. Res. 2015, 153, 512-525. [CrossRef]

19. Wu, H.; Hayes, M.J.; Weiss, A.; Hu, Q. An evaluation of the Standardized Precipitation Index, the China-Z Index and the statistical Z-Score. Int. J. Climatol. 2001, 21, 745-758. [CrossRef]

20. Morid, S.; Smakhtin, V.; Moghaddasi, M. Comparison of seven meteorological indices for drought monitoring in Iran. Int. J. Climatol. 2006, 26, 971-985. [CrossRef]

21. Kraus, E. Subtropical droughts and cross-equatorial energy transports. Mon. Weather Rev. 1977, 105, 1009-1018. [CrossRef]

22. van Rooy, M.P. A Rainfall Anomaly Index (RAI), independent of the time and space, Notos. Weather Bur. S. Afr. 1965, 14, 43-48.

23. Gibbs, W.J.; Maher, J.V. Rainfall Deciles as Drought Indicators; Bureau of Meteorology: Melbourne, Australian, 1967.

24. Triola, M.F. Elementary Statistics; Addison-Wesley: Reading, MA, USA, 1995.

25. Woo, S.B.; Nam, W.H.; Kim, T. Spatiotemporal Agricultural Drought Damage and Its Relationship with Hydrometeorological Characteristics of Historical Drought Events for Recent 40 Years. In Proceedings of the Korea Water Resources Association Conference, Seoul, Korea, 24 June 2020; p. 392. 